\title{
Comparative Analysis of Stockpile Volume Estimation using UAV and GPS Techniques*
}

\author{
${ }^{1}$ S. Mantey and ${ }^{1}$ M. S. Aduah \\ ${ }^{1}$ University of Mines and Technology, Box 237, Tarkwa, Ghana
}

Mantey, S. and Aduah, M. S., (2021), "Comparative Analysis of Stockpile Volume Estimation using UAV and GPS Techniques”, Ghana Mining Journal, Vol. 21, No. 1, pp. 1-10.

\begin{abstract}
Mining operations involve the extraction of minerals of economic value from the earth. In surface mining operations, overburdens need to be stripped in other to reach the ore. Large volumes of waste as well as ore is stripped in the process. Various technologies have been used to aid in stockpile volume estimation. Notable among them are the Total Stations and Global Positioning Systems (GPS). However, labour, safety and time has challenged the use of these technologies. Unmanned Aerial Vehicle (UAV), commonly known as drone is an emerging technology for stockpile volume computations in the Mine. UAV technology for data collection is less labour intensive, safer and faster. Therefore, this study applied the UAV technology in an open pit to estimate stockpile volumes from a Mine. For the purpose of this study, GPS and UAV data were collected for measuring stockpile volumes of materials mined. The actual volumes of stockpiles A, B, C, D (Case 2), produced differences of $0.05 \%$ for $\mathrm{A}, 0.05 \%$ for $\mathrm{B}, 0.08 \%$ for $\mathrm{C}, 0.07 \%$ for $\mathrm{D}$ and $0.03 \%$ for $\mathrm{A},-0.03 \%$ for $\mathrm{B}, 0.03 \%$ for $\mathrm{C}$ and $0.04 \%$ for $\mathrm{D}$, for the GPS-based and the UAV-based techniques, respectively. The GPS-based technique generated moderate accuracies for volume estimation, but was time consuming and labour intensive, compared to the UAV-based technique; which was faster and less labour intensive. The UAV-based technique was the most accurate, safest and is capable of mapping large areas rapidly. It is therefore recommended that UAV survey be incorporated in stockpile volume estimation.
\end{abstract}

Keywords: UAV, GPS, Stockpile, Mine, Total Stations

\section{Introduction}

Mining operations involve the extraction of precious minerals in the form of ore from the earth for both commercial and non-commercial purposes. Mining operations to exploit the ore are normally done either by underground or surface mining. In surface mining operations, overburdens need to be stripped in other to reach the ore. Large volume of waste materials as well as ore is stripped in the process (Suleman and Baffoe, 2017). Volumes of both waste and ore mined is important to both mine contractors and mine managers. Mine contractors and workers are paid on the basis of volume of materials mined. Moreover, the efficiency of mine equipment is measured by the amount of materials mined in a specified period. Also, the productivity of the mine is measured based on the amount of materials mined within a given period. In the Mines, Land Surveyors are responsible for estimating the amount of waste and ore that are mined in a day, a week, or a month. This is usually achieved by surveying the stockpile, waste dump and within the active pits. Over the years, various technologies and techniques have been developed to help surveyors collect data for volume purposes. Notable among them are the Total Stations and Global Positioning Systems (GPS) (Arango and Morales, 2015; Fitzpatrick, 2015). However, the use of these technologies in collecting data for volume estimation is often labour intensive, sometimes involves surveyors working in hazardous and unsafe environment (Labant et al., 2013; Barry and Coakley, 2013). In addition, relatively long time is required on the field to collect data for volume estimation. In areas where surveyors cannot access, no data is collected and hence reduces the quality and richness of the data collected (Rathore and Kumar, 2015). Data collected by Total Station and GPS technology is based on the judgement, experience and intuition of the user and hence the quality vary from user to user. In using the GPS technology, it becomes difficult to track GPS signals as the pit narrows down and deeper. It is very stressful, tedious and time consuming when collecting data for daily, weekly and monthly volume estimation using the conventional techniques. Unmanned Aerial Vehicle (UAV), commonly known as drone is an emerging technology which is an aircraft without human pilot on board and has its application also in the Mine (Mantey and Tagoe, 2019; Miljkovi'c et al., 2017; Cryderman et al., 2014; Merz and Chapman, 2011; Everaerts, 2008; Valavanis, 2008). UAV technology has the potential to reduce the stress and the manual effort involved in surveying, mapping and data collection (Mantey and Tagoe, 2019; Rathore and Kumar, 2015 Manyoky et al., 2011). UAVs are becoming increasingly important for the purpose of 3D mapping or volume computation in an open pit mining industry (Park et al., 2016; Cryderman et al., 2014; Witayangkurn et al., 2011). UAV can make a major impact in the mining industry in terms of productivity, cost and efficiency. It is less time consuming in collecting data over large areas without loss in accuracy. UAV technology offers far richer data than the conventional survey techniques (Barry and Coakley, 2013; Darwin et al., 2013). Inaccessible areas are accessed without compromising the safety of the surveyor (Incekara 
et al., 2016; Raeva et al., 2016; Lippiello and Siciliano, 2012). This study compares UAV and GPS-based methods to estimate stockpile volume of materials mined in an open pit mine in Ghana.

\subsection{Methods of Estimating Volume}

Volume of earthworks can be estimated using a variety of methods. The method used is based on the availability of existing data or measured data. Volumes could be computed as a product of crosssections, spot heights and contour area methods (Ghilani and Wolf, 2012; Kavannagh and Glenn Bird, 2000).

\subsubsection{Volumes from Cross-Section Method}

The cross-section method is mainly used to compute volume on a linear construction projects such as highways, railways and canals. In this method, the centre line of the project is determined and divided into ground profile called cross-sections at regular intervals. The area of each cross-section is computed and the height or depth measured as well. The volume is computed as a product of the area and the height or depth (Ghilani and Wolf, 2012; Kavannagh and Glenn Bird, 2000). Equation (1) shows the formula for the cross-section method.

Volume $=$ Cross sectional Area $\times$ Height

Two methods of computing volume under the crosssection method are the End Area Method and Prismoidal Method.

End Area Method: The End Area Method is used to compute the average volume between two stations separated by a horizontal distance. The volume between the two stations is equal to the average of the end areas multiplied by the horizontal distance between them (Ghilani and Wolf, 2012; Kavannagh and Glenn Bird, 2000). The End Area Method utilises the areas of parallel cross-sections at regular intervals through the proposed earthwork volume. The cross-sections can be paced at intervals depending on the size of the site and required accuracy. The cross-sections are aligned perpendicular to a baseline that extends the entire length of the excavated area (Essa, 1992). For a particular cross-section, the volume can be computed using Equation (2):

$$
\begin{gathered}
\text { Volume }= \\
(\mathrm{d} 1(A 1+A 2)) / 2
\end{gathered}
$$

For $\mathrm{N}$ cross-sections, the general formula becomes Equation (3):

$$
\begin{gathered}
\text { Volume }= \\
(\mathrm{d}[A 1+A N+2(A 2+A 3+\cdots A N-1)]) / 2
\end{gathered}
$$

where, $\mathrm{A} 1=$ area of first cross-section, $\mathrm{AN}=$ area of last cross section, $\mathrm{A} 2=$ area of prime cross-section, $\mathrm{A} 3=$ area of even cross-section and $d=$ length of baseline.

The end area method will give accurate results if the cross-sections are of the same order.

Prismoidal Method: The prismoidal method applies to volumes of all geometric solids that can be considered prismoid. The volume contained between a series of cross-sections at constant distance apart can be approximated to be a prismoid, a solid figure with plane parallel ends and plane sides (Ghilani and Wolf, 2012). The prismoidal method is useful when the ground is not uniform or significantly irregular between cross-sections. This method adds additional cross-sectional area midway between the two cross-sections defining the volume being calculated (Goktepe and Lav, 2003). For a series of three cross-sections, the volume contained between them is given by Equation (4):

$$
\begin{gathered}
\text { Volume }(1-3)= \\
(\mathrm{d}[A 1+4 A 2+A 3]) / 3
\end{gathered}
$$

For $\mathrm{N}$ cross-sections, the general formula is given by Equation (5):

$$
\begin{array}{r}
\text { Volume }=\left(\mathrm { d } \left[\text { A } 1+A N+4 \sum \text { even areas }+\right.\right. \\
\left.\left.2 \sum \text { remaining odd areas }\right]\right) / 3
\end{array}
$$

where, $\mathrm{A} 1=$ area of first cross section, $\mathrm{AN}=$ area of last cross section, and $\mathrm{d}=$ length of baseline.

For the prismoidal approach, the number of crosssection must be odd.

\subsubsection{Volumes from Spot Heights Method}

The spot heights method is used to obtain the volume of large deep excavations such as basements, where the formation level is sloping, horizontal or terraced. In this approach, a square, rectangular or triangular grid is established on the ground and the heights are measured at a regular interval (Ghilani and Wolf, 2012). The spot height approach of volume computation produces better result for smaller grid than larger grid but involves intense field work. The total volume is given by Equation (6):

$$
\begin{gathered}
\text { Volume }= \\
\left(\mathrm { A } \left[\sum \text { single depths }+\sum \text { even double depths }+\right.\right. \\
\left.\left.3 \sum \text { triple depths }+4 \sum \text { quadruple depths }\right]\right) / 4
\end{gathered}
$$

\subsubsection{Volumes from Contour Area Method}

The contour area method uses the area of the excavated elevation contour lines to determine volumes. From a topographic map of the site, the 
areas enclosed by regular contour intervals are measured. The area measurement can be done by hand with a planimeter, electronic digitiser, or directly with a computer aided design (CAD) program. If the horizontal areas enclosed by each contour line are large relative to the elevation difference between the two contour elevations, averaging the two areas and multiplying the average by the height difference would estimate the volume (Ghilani and Wolf, 2012).

\subsection{Equipment for Estimating Volume}

Some equipment available for volume estimation are Total Stations and GPS (Fitzpatrick, 2015; Ghilani and Wolf, 2012; Kavannagh and Glenn Bird, 2000) and recently UAV. Study on accuracy, time, safety and cost have been conducted to compare some of the techniques available (Wang et al., 2017). In Mine surveying, UAVs could be used in pit and waste dump management, stockpile management and mapping of steep inaccessible inclines. Also, UAVs could be used for fleet management, road maintenance, and water management in Mine sites (Lee et al., 2015). Besides, the UAV technology could be used in the drilling and blasting processes which allow an organisation to manage the Mine site before and after blasting and identifying misfires or wall damages (Lee and Choi, 2016). More so, UAVs could be used for Mine safety operations such as storm damage assessment, surface stability monitoring, joint mapping, dust monitoring and slope stability analysis (Lee et al., 2015). Additionally, it could be used during construction by monitoring and reporting the progress of a Mine site. Other applications could be conveying belt inspections, ground heating monitoring, or facility management (Lee and Choi, 2016; Choi and Lee 2011). Most mining companies have started using the UAV technology for mine surveying purposes especially stockpile volume estimation. Utilising UAV technology for data collection has three unique advantages: low initial investment; low mobilisation cost; and decreased time required to complete data acquisition (Wang et al., 2017; Fitzpatrick, 2015). It is faster in collecting data over large areas without loss in accuracy. UAV technology offers far richer data than conventional survey techniques (Lee and Choi, 2016; Barry and Coakley, 2013; Choi and Lee 2011). In addition, when collecting data for volume purposes using UAV, there is no need to climb stockpiles, no need to go around hazardous areas, hence reducing the possibility of accident. In collecting data for pit face updates and pit volume computation using UAV, there is an increase in productivity and safety since there is no need for digger operators and dump trucks to stop moving and no need for surveyors to be under diggers. Inaccessible areas are accessed without compromising the safety of surveyors (Incekara $e t$ al., 2016). The accuracy of UAV data for volume measurement compared to conventional techniques such as a Total Station has been evaluated and proven better than the conventional method (Raeva et al., 2016; Park et al. 2016). Figs. 1 and 2 show a Total Station and GPS receiver respectively.

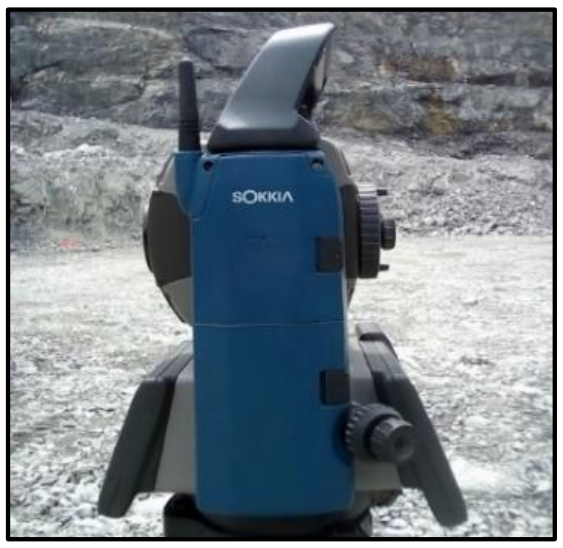

Fig. 1 Total Station

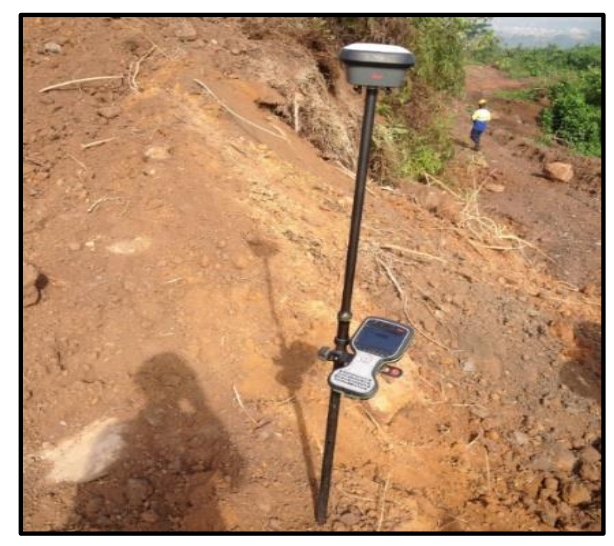

Fig. 2 Leica GPS Receiver

\section{Resources and Methods Used}

\subsection{Resources}

The resources used in this study include: Leica GPS Receiver and DJI Phantom 4 Pro UAV (Fig. 3); data collected from a large scale Mine in Ghana using GPS survey technique and UAV technique; drone deploy to plan the flight; Agisoft Photomodeler mapper to process the images acquired; Surpac software to process the GPS survey data and to compute the volume. 


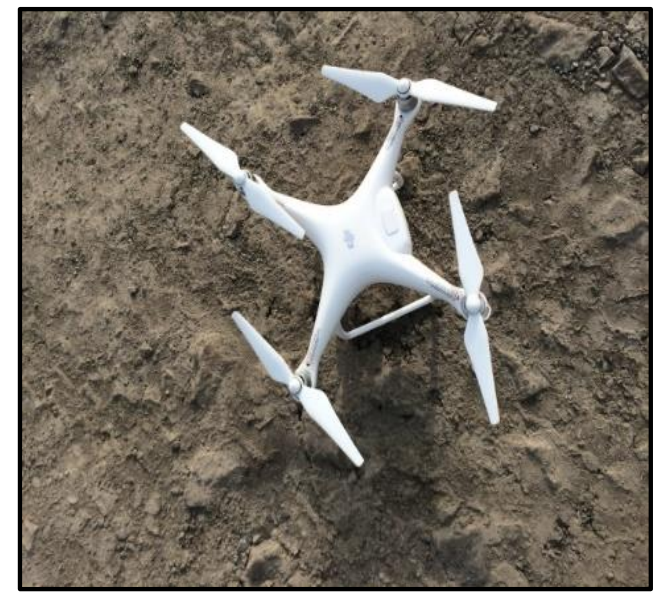

Fig. 3 DJI Phantom 4 Pro UAV

\subsection{Methods Used}

The methods used to estimate volume of materials mined in an open pit are discussed in the following subsections: GPS survey; drone survey; processing of GPS survey data; processing of drone survey data and volume estimation. For the purpose of this work, data was collected in two folds: end of February 2020; and first week of March 2020.

\subsubsection{GPS Survey}

In GPS survey, two or more receivers are required. One of the receivers is used as base and the others as rover. The GPS technology also has a logger on which all the data is stored. The base station used in this study is a COR-Station and all the other receivers were connected to it. The data collected for volume estimation in this study include; toe (the lower limit of a bench) and crest (the upper limit of a bench) of the various stockpiles. The measurements were done at regular intervals. For crest and toe data, the data were collected based on the geometry or shape of the crest and toe. This was done as much as possible to depict the stockpile. Fig. 4 shows a surveyor picking the crest and toe.

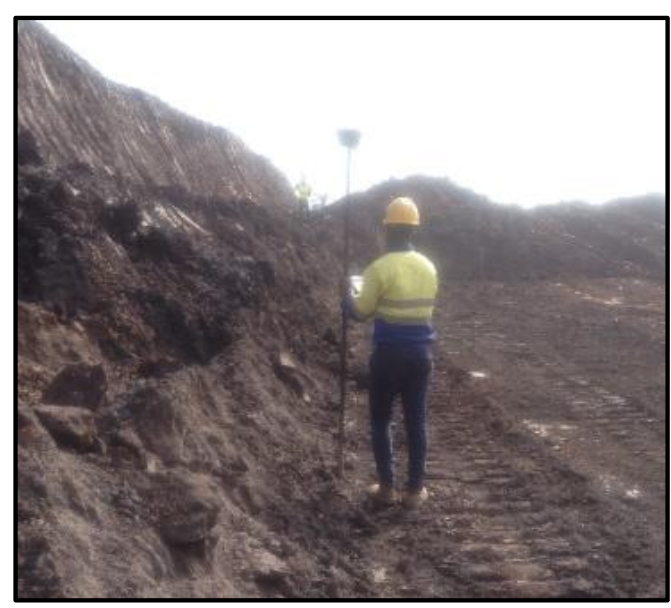

Fig. 4 Picking Crest and Toe with GPS Receiver

\subsubsection{UAV Survey}

Prior to the drone survey, camera calibration was carried out and the following steps carried out as follows:

Field Visit: The Mine site to be surveyed was visited to ascertain the weather condition, the extent of the area to be surveyed, suitable areas to establish ground control points, and suitable place to take-off and land the drone.

Flight Planning: The mission was planned using a drone deploy software. The flight was planned at an altitude of $80 \mathrm{~m}$ with $80 \%$ and $60 \%$ overlap and side laps respectively. The flight was also planned in such a way that data is collected at every meter interval.

Establishment of Ground Control Points: Ground Control Points (GCPs) provide a means of orienting images to the ground (Raeva et al., 2016; Remondino et al., 2011). In establishing GCPs, it is required that the GCPs are: easily defined and identifiable; locatable with high precision and high contrast to the background (Raeva et al., 2016). After the mission was planned, suitable areas were selected to establish the GCPs. The GCPs were established at areas where they will be visible and identified in the captured images and also well distributed. This helps to reduce the accumulation of errors and hence increase the accuracy of the data collected. For the purpose of this study, six (6) sharp and well-defined GCPs were distributed within the area to be surveyed. Fig. 5 shows a surveyor marking a GCP on the ground.

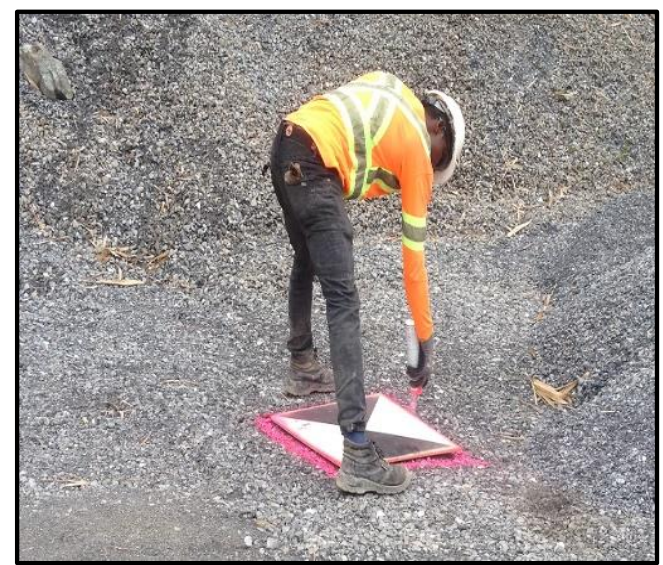

Fig. 5 Establishment of Ground Control Point

Survey of Ground Control Points (GCPs): The GCPs established were then surveyed to acquire the positions ( $\mathrm{x}$ and $\mathrm{y}$ ) and elevations $(\mathrm{z})$ of each point using the Leica (GS18) GPS. Figure 6 shows surveyors making observation on GCP established. 


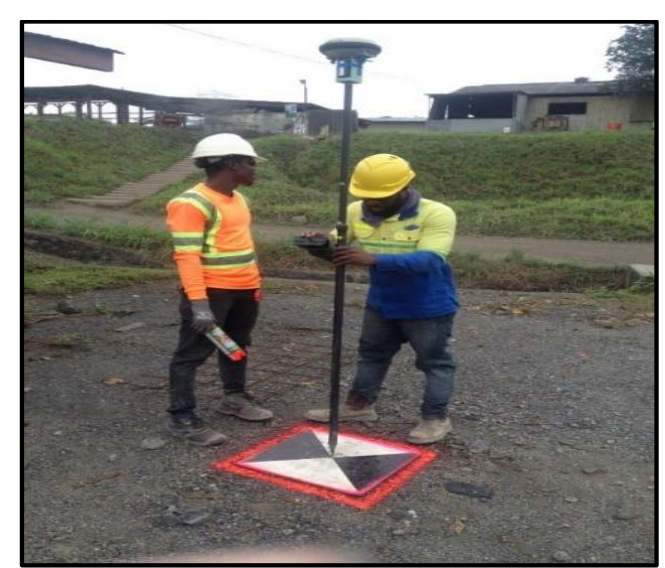

Fig. 6 Survey of Ground Control Point

Image Acquisition: The images were acquired using a DJI Phantom 4 Pro platform which is a rotor-wing type of UAV. The camera on board was PhantomVisionFC 4000, the size of the sensor was $4000 \times 3000 \mathrm{~mm}$ with 12 mega pixel resolution and a focal length of 3.6125 .

\subsubsection{Data Processing}

The data acquired were processed for both GPS and UAV images. Geovia Surpac 6.6.2 software was used to process the GPS data and Agisoft Photomodeler was used to process the images obtained from the UAV survey.

GPS Data Processing: The raw data collected on the field was downloaded from the logger to Microsoft Excel. The data was edited and string number, string ID, Northern (N), Eastern (E) and Elevation (Z) were assigned to the data. String files were created from the CSV (comma delimitated) created in Excel using Geovia Surpac software.

UAV Image Processing: Image processing was done to bring each image together to form a $3 \mathrm{D}$ scene of the study area. Images were georeferenced and DTM file created. The volume of materials mined were estimated using the DTM generated from the data collected using the UAV and GPS technique. The method used to estimate the volume of materials mined was the cut and fill between DTMs method. However, the algorithm behind the cut-fill method was the End Area Method as this method produced the best standard deviation of 0.55 . Delaunay triangles were formed during the DTM generation. The volume contained within the triangle is estimated by multiplying the area by the average height.

\section{Results and Discussion}

\subsection{Results}

The orthophoto of the study area in Fig. 7 shows the positions of control points and checkpoints as well as the stockpiles A, B, C and D (Fig. 8). The accuracies of the control points and checkpoints were determined for the $\mathrm{X}, \mathrm{Y}, \mathrm{Z}$ positions measured from GPS observations and from the UAV images captured (Tables 1 and 2). In computing the volumes from the UAV images, the lower and upper surfaces of the stockpiles were considered (Figs. 9 to 14). Tables 3 to 6 show the results of the stockpile volumes obtained from GPS and UAV surveys as well as the actual volumes determined by measuring the mined materials under weighbridges for the purpose of this study and assumed as the ideal volumes. The volumes of stockpile $\mathrm{D}$ with conveyor belt (case 1) (Fig. 13) computed from GPS and UAV were $15428.912 \mathrm{~m}^{3}$ and $15432.593 \mathrm{~m}^{3}$ respectively. The volume of stockpile $\mathrm{D}$ with conveyor belt could not be measured under weighbridge to determine the actual volume for comparison due to the conveyor belt. To assess the accuracy of the UAV survey, Root mean square (RMS) errors as well the 95\% confidence level of the check points and control points were determined.

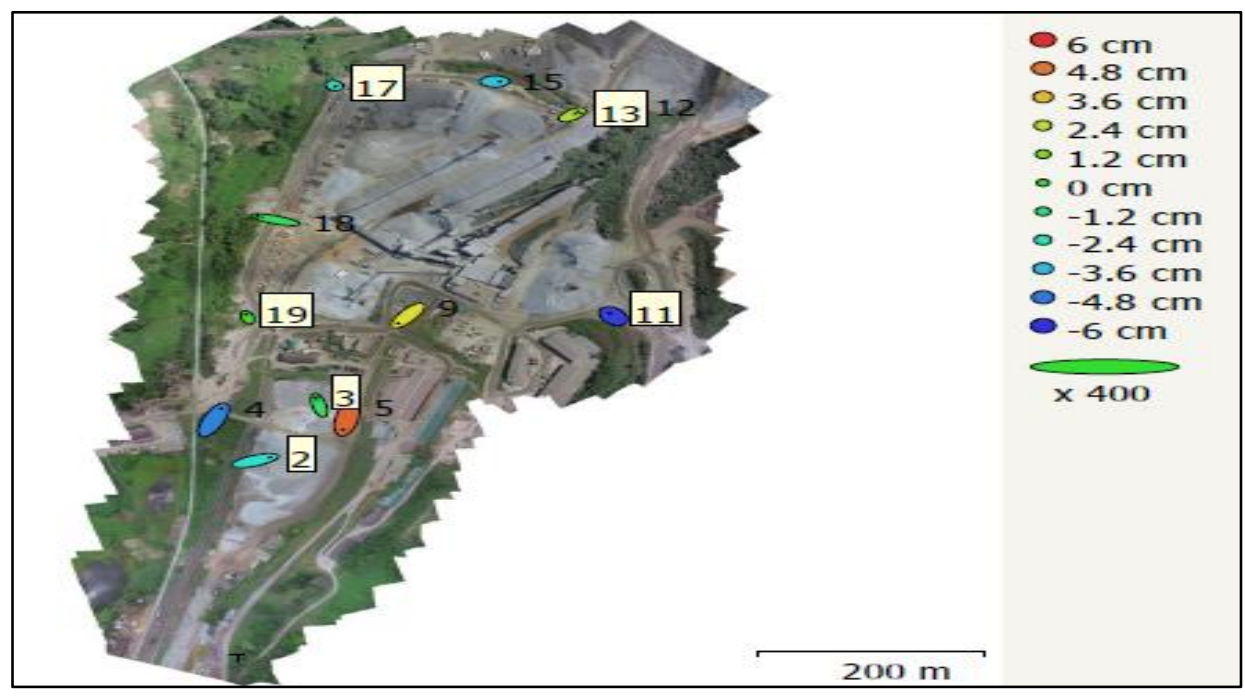

Fig. 7 Orthophotos with Ground Control and Check Points 
Table 1 Control Point Accuracies

\begin{tabular}{|c|c|c|c|c|c|}
\hline Label & $\begin{array}{c}\text { X-error } \\
(\mathrm{cm})\end{array}$ & $\begin{array}{c}\text { Y-error } \\
(\mathrm{cm})\end{array}$ & $\begin{array}{c}\text { Z-error } \\
(\mathrm{cm})\end{array}$ & $\begin{array}{c}\text { Total } \\
\text { Error }(\mathrm{cm})\end{array}$ & $\begin{array}{c}\text { Image } \\
\text { (pix) }\end{array}$ \\
\hline 2 & $\mathbf{6 . 6 0 4 0}$ & $\mathbf{2 . 4 5 6 2}$ & -2.7749 & 7.5727 & 0.3290 \\
\hline 4 & $\mathbf{3 . 3 7 7 9}$ & $\mathbf{8 . 3 5 5 3}$ & -4.5965 & 10.1167 & 0.3790 \\
\hline 5 & -1.6080 & -8.5320 & $\mathbf{5 . 0 9 9 5}$ & 10.0682 & 0.2630 \\
\hline 9 & -4.3534 & -6.0113 & 2.9940 & $\mathbf{8 . 0 0 3 2}$ & 0.4790 \\
\hline 11 & -1.4499 & $\mathbf{2 . 1 9 0 1}$ & $-\mathbf{5 . 7 6 1 5}$ & 6.3320 & 0.6600 \\
\hline 12 & -2.8566 & -0.2727 & 4.2837 & $\mathbf{5 . 1 5 6 0}$ & 0.5290 \\
\hline 15 & 2.2846 & -0.0012 & -3.4813 & 4.1639 & 0.6760 \\
\hline 17 & 0.4322 & -0.4302 & -2.4202 & 2.4959 & 0.6520 \\
\hline 19 & -0.6782 & 2.3322 & 0.2352 & 2.4402 & 0.4440 \\
\hline Total & $\mathbf{3 . 2 0 9 2}$ & 4.6578 & $\mathbf{3 . 8 4 9 6}$ & 6.8420 & 0.5200 \\
\hline
\end{tabular}

Table 2 Check Point Accuracies

\begin{tabular}{|c|c|c|c|c|c|}
\hline Label & $\begin{array}{c}\text { X-error } \\
(\mathrm{cm})\end{array}$ & $\begin{array}{c}\text { Y-error } \\
(\mathrm{cm})\end{array}$ & $\begin{array}{c}\text { Z-error } \\
(\mathrm{cm})\end{array}$ & $\begin{array}{c}\text { Total } \\
\text { Error (cm) }\end{array}$ & Image (pix) \\
\hline 3 & -1.4040 & 6.1373 & -0.8370 & 6.3513 & $0.2050(9)$ \\
\hline 13 & 2.8308 & 2.3121 & 2.0889 & 4.2098 & $0.6750(20)$ \\
\hline 18 & -8.0709 & 2.6016 & -0.6702 & 8.5063 & $0.3960(8)$ \\
\hline Total & $\mathbf{5 . 0 0 4 1}$ & 4.0735 & 1.3556 & 6.5934 & 0.5390 \\
\hline
\end{tabular}

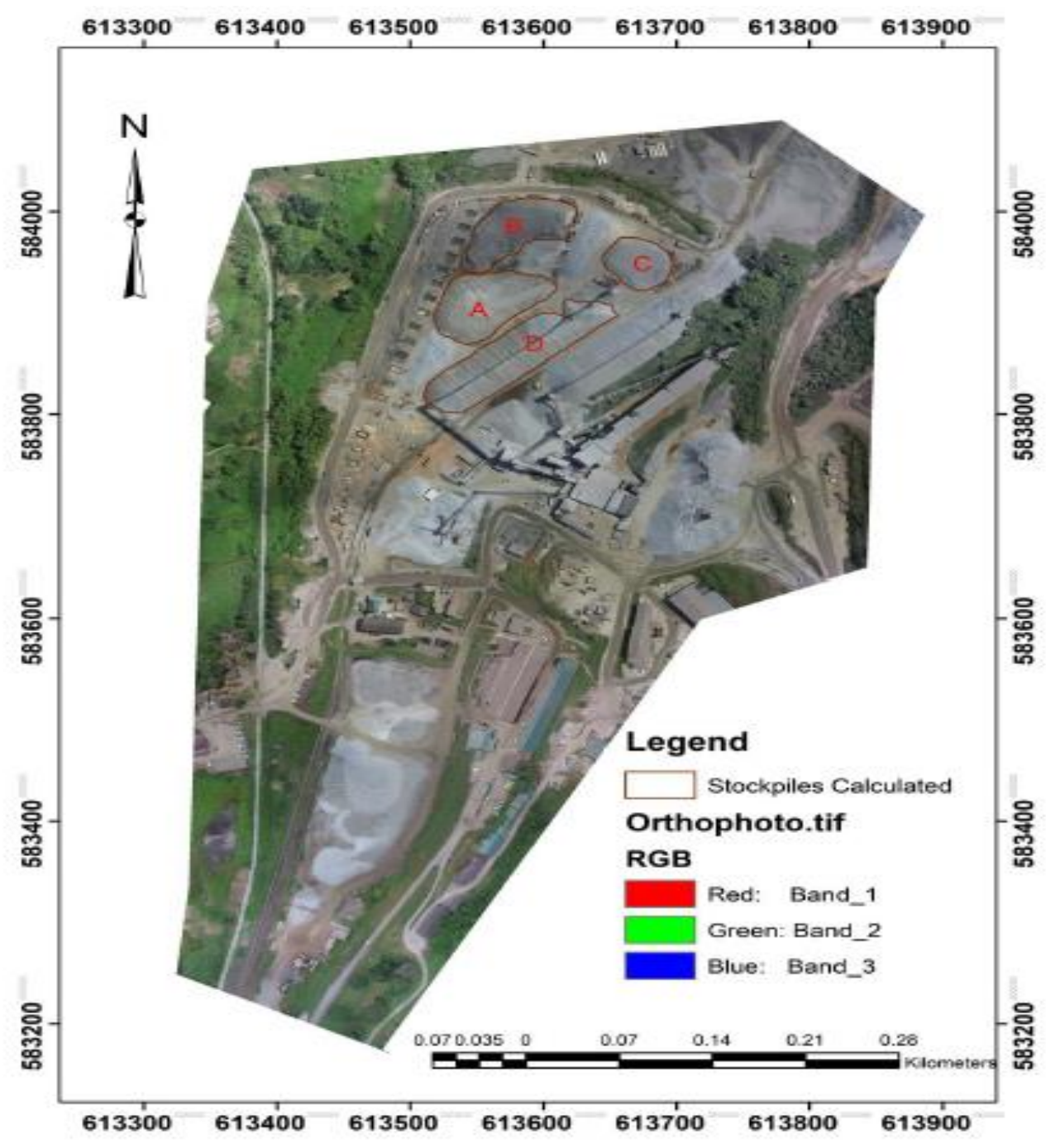

Fig. 8 Orthophotos showing Stockpiles A, B, C and D 


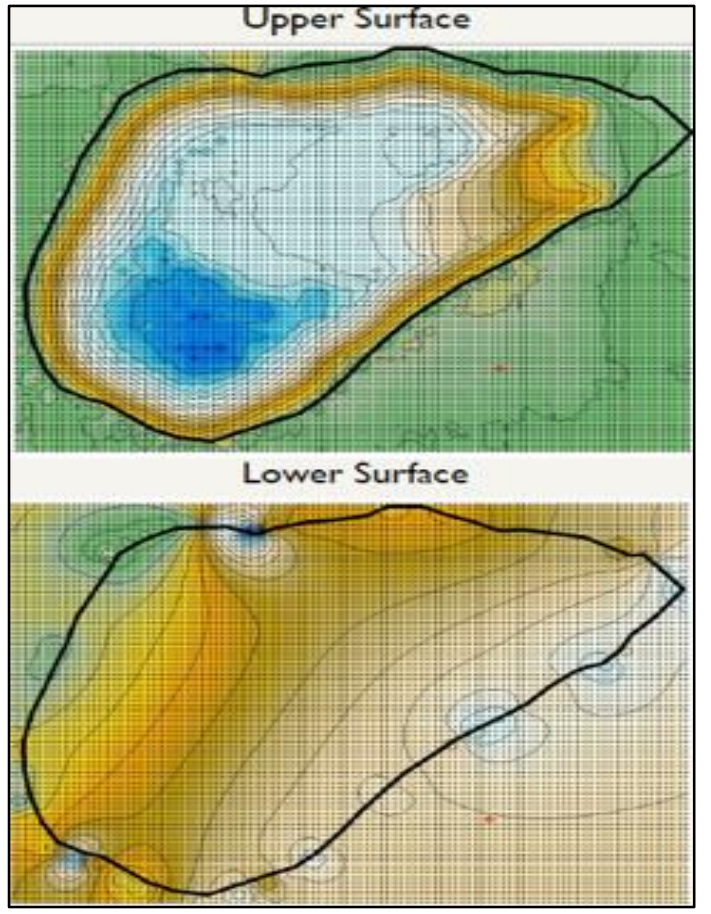

Fig. 9 Upper and Lower Surface of Stockpile A

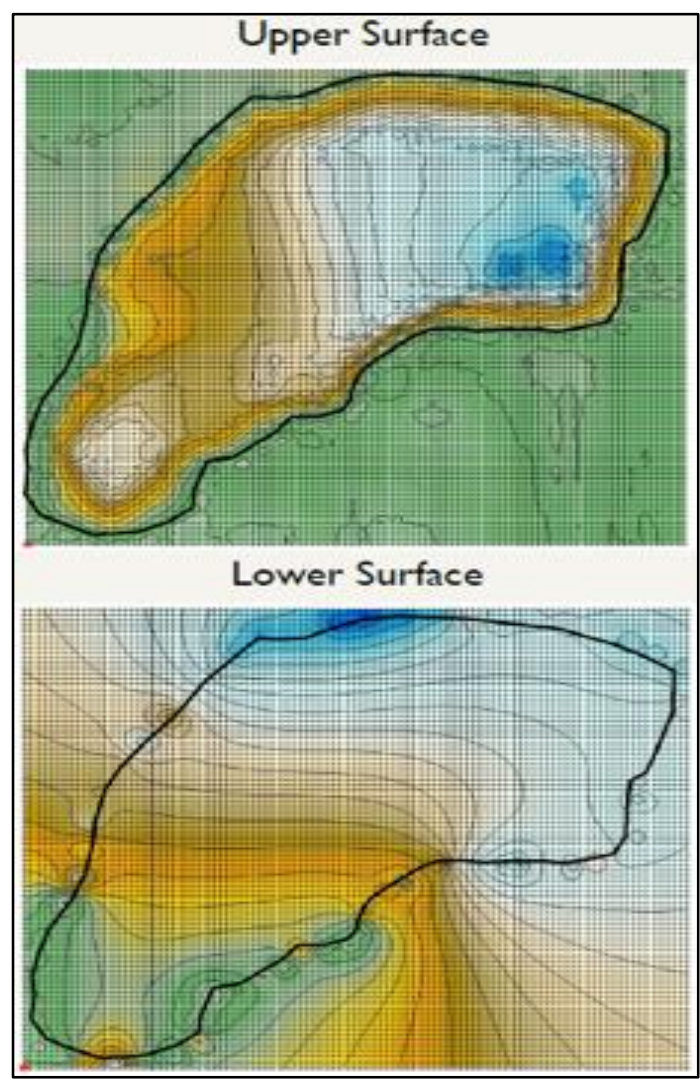

Fig. 10 Upper and Lower Surface of Stockpile B

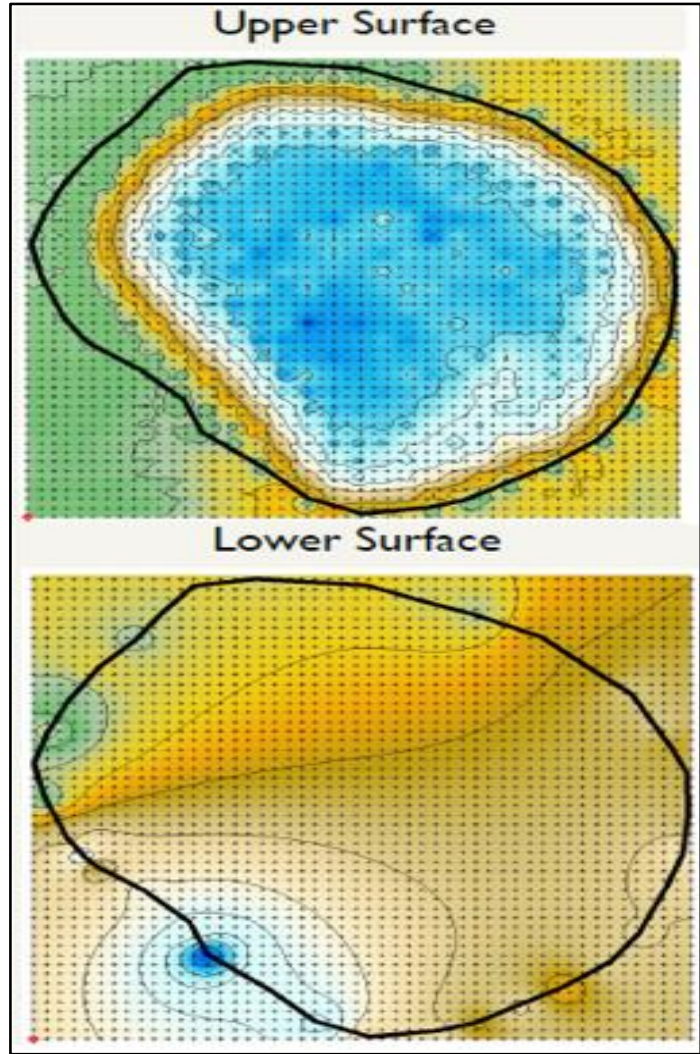

Fig. 11 Upper and Lower Surface of Stockpile C

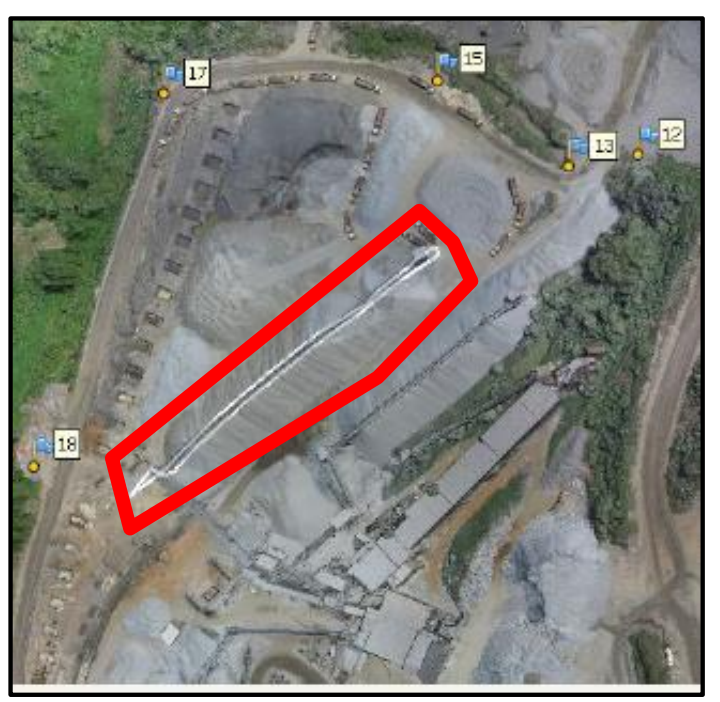

Fig. 12 Orthophoto of Stockpile D with Conveyor Belt 


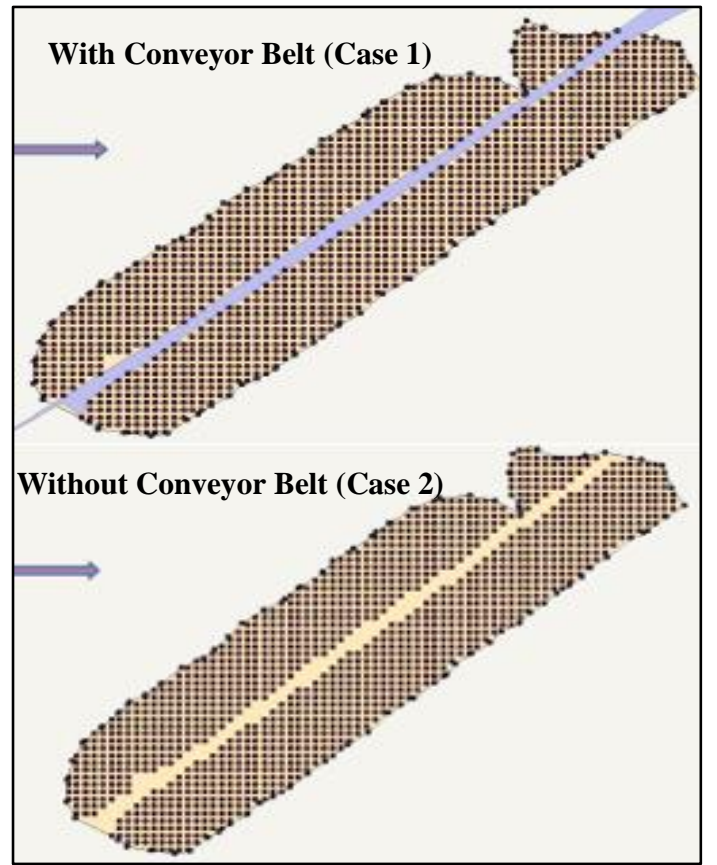

Fig. 13 Upper Surface of Stockpile D with and without Conveyor Belt

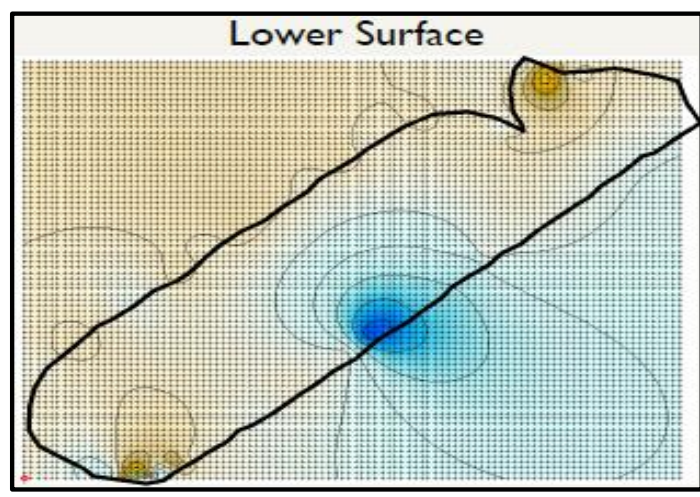

Fig. 14 Lower Surface of Stockpile D

Table 3 Stockpile A

\begin{tabular}{|l|c|c|c|}
\hline & $\begin{array}{c}\text { Volume } \\
\mathbf{m}^{\mathbf{3}}\end{array}$ & $\begin{array}{c}\text { Difference } \\
\mathbf{m}^{\mathbf{3}}\end{array}$ & $\begin{array}{c}\text { Percentage } \\
\text { Difference }\end{array}$ \\
\hline Actual & 19040.250 & - & - \\
\hline GPS & 19030.334 & 9.916 & $0.05 \%$ \\
\hline UAV & 19035.100 & 5.150 & $0.03 \%$ \\
\hline
\end{tabular}

Table 4 Stockpile B

\begin{tabular}{|l|c|c|c|}
\hline & $\begin{array}{c}\text { Volume } \\
\mathbf{m}^{\mathbf{3}}\end{array}$ & $\begin{array}{c}\text { Difference } \\
\mathbf{m}^{\mathbf{3}}\end{array}$ & $\begin{array}{c}\text { Percentage } \\
\text { Difference }\end{array}$ \\
\hline Actual & 15117.517 & - & - \\
\hline GPS & 15110.257 & 7.26 & $0.05 \%$ \\
\hline UAV & 15122.237 & -4.72 & $-0.03 \%$ \\
\hline
\end{tabular}

Table 5 Stockpile $\mathbf{C}$

\begin{tabular}{|l|c|c|c|}
\hline & $\begin{array}{c}\text { Volume } \\
\mathbf{m}^{\mathbf{3}}\end{array}$ & $\begin{array}{c}\text { Difference } \\
\mathbf{m}^{\mathbf{3}}\end{array}$ & $\begin{array}{c}\text { Percentage } \\
\text { Difference }\end{array}$ \\
\hline Actual & 15112.011 & - & - \\
\hline GPS & 15100.222 & 11.789 & $0.08 \%$ \\
\hline UAV & 15108.010 & 4.001 & $0.03 \%$ \\
\hline
\end{tabular}

Table 6 Stockpile D (Case 1) with Conveyor Belt

\begin{tabular}{|l|c|c|c|}
\hline & $\begin{array}{c}\text { Volume } \\
\mathbf{m}^{\mathbf{3}}\end{array}$ & $\begin{array}{c}\text { Difference } \\
\mathbf{m}^{\mathbf{3}}\end{array}$ & $\begin{array}{c}\text { Percentage } \\
\text { Difference }\end{array}$ \\
\hline Actual & - & - & - \\
\hline GPS & 15428.912 & - & - \\
\hline UAV & 15432.593 & - & - \\
\hline
\end{tabular}

Table 7 Stockpile D (Case 2) without Conveyor Belt

\begin{tabular}{|l|c|c|c|}
\hline & $\begin{array}{c}\text { Volume } \\
\mathbf{m}^{\mathbf{3}}\end{array}$ & $\begin{array}{c}\text { Difference } \\
\mathbf{m}^{\mathbf{3}}\end{array}$ & $\begin{array}{c}\text { Percentage } \\
\text { Difference }\end{array}$ \\
\hline Actual & 14419.977 & - & - \\
\hline GPS & 14430.243 & -10.266 & $0.07 \%$ \\
\hline UAV & 14414.430 & 5.547 & $0.04 \%$ \\
\hline
\end{tabular}

\subsection{Discussion}

The use of UAVs to estimate volume of materials mined has proven beneficial than conventional techniques. Relatively longer time was spent in data collection using GPS technique compared to the UAV technique for the same area. For the GPS survey, about eighty-two minutes ( 82 mins) was used to complete data capturing whiles twelve minutes (12 mins) was used to acquire data by the UAV technique. Four (4) personnel were involved in collecting data using the GPS technique while two (2) persons were involved in the data collection using UAV technique. The UAV technique yielded a relatively better result than the GPS survey when compared to the actual volumes computed from the weighbridge (Tables 3 to 7). The percentage differences between the UAV and actual volumes were consistently lower than those between the GPS volumes and the actuals (Tables 3 to 7). The UAV data provided a better appreciation and topography of the stockpiles compared to the GPS survey due to the dense point clouds from the UAV.

\section{Conclusions and Recommendation}

This study demonstrates the use of a UAV for stockpile volume estimation. In this study, the conventional method with GPS to estimate volumes of stockpile were compared with UAV data from the same site. The results were compared with the actual volume of mined material which was determined from weighbridges. Comparing the results of the GPS with the actual volumes of stockpiles A, B, C, $\mathrm{D}$ (Case 2), it was found that there were $0.05 \%$, $0.05 \%, 0.08 \%$ and $0.07 \%$ differences while the volumes computed from the UAV compared to the actual volumes from stockpiles A, B, C, D (Case 2) also produced $0.03 \%,-0.03 \%, 0.03 \%$ and $0.04 \%$ differences respectively. These results suggest that the estimated volumes from UAV data are more accurate. Additionally, comparing the time taken to get the data for the both UAV and GPS, it was concluded that the UAV is about 6 times faster than 
the GPS. UAV technique is a promising method that could be used to complement ground survey technique in volume estimation. This study recommends that UAV survey should be incorporated in stockpile volume estimation for better, safer and faster results.

\section{References}

Arango, C. and Morales, C. A. (2015), "Comparison between multicopter UAV and Total Station for estimating stockpile volumes", The international Archives of the Photogramme-try, Remote Sensing and Spatial Information Sciences, 2015, XL-1/W4, pp. 131-135.

Barry, P. and Coakley, R. (2013), "Accuracy of UAV Photogrammetry Compared with Network RTK GPS", The International Archive of Photogrammetry and Remote Sensing, Vol. 2, pp. 2731.

Choi, K. and Lee, I. (2011), “A UAV-Based CloseRange Rapid Aerial Monitoring System for Emergency Responses", The International Archives of the Photogrammetry, Remote Sensing and Spatial Information Sciences, Vol. 38, pp. 247-252.

Cryderman, C., Mah, S. B. and Shufletoski, A. (2014), "Evaluation of UAV photogrammetric accuracy for mapping and earthworks computations", Geomatica, Vol. 68, pp. 309-317.

Darwin, N., Hamid, N. F. A., Udin, W. S. and Mohd, N. A. B., (2013), "Light Weight Rotatory-Wing UAV for large scale mapping applications", Asia Geospatial Forum, Kuala Lumpur, Malaysia, pp. 24-26.

Easa, S. (1992), "Discussion of Cut and Fill Calculations by Modified Average-End-Area Method by James W. Epps and Marion W. Corey (September-October, 1990, Vol. 116, No. 5)", Journal of Transportation Enginee-ring, 118(4), pp. 600-601.

Everaerts, J., (2008), “The Use of Unmanned Aerial Vehicles ( UAVS ) for Remote Sensing and Mapping", The international Archives of the Photogrammetry, Remote Sensing and Spatial Information Sciences, Vol. 37, pp. 1187-1192.

Fitzpatrick, B. P. (2015), "Unmanned Aerial Systems for Surveying and Mapping: Cost Comparison of UAS Versus Traditional Methods of Data Acquisition", Published Doctoral dissertation, University of Southern California, pp. 7-47.

Ghilani, C. D. and Wolf, P. R. (2012), "Elementary Surveying: An Introduction to Geomatics", Person Education Inc., New Jessy, $13^{\text {th }}$ edition, pp. 212 - 358.

Goktepe, A. B., and Lav, A. H. (2003), "Method for Balancing Cut-Fill and Minimizing the Amount of Earthwork in the Geometric Design of Highway", Journal of Transport-ation Engineering, Vol.
129, No 5, pp. 564-571.

Incekara, A. H., Yildirim, O., Susam, T., and Seker, D. Z. (2016), "Using Unmanned Aerial Vehicles for Open Mining Areas: Current Applications and Future Potentials", Gaziosmanpasa University, Department of Geomatics Engineering, 60150, Tokat Turkey, 06 pp.

Kavannagh, B. F. and Glenn Bird, S. J., (2000), "Surveying: Principles and Applications", 5th Edition, Prentice Hall, Incorporated, Pearson Education, Upper Saddle River, New Jersey pp. 546-599.

Labant, S., Sta`nková, H., and Weiss, R. (2013), "Geodetic determining of stockpile volume of mineral excavated in open pit mine", Geosciences Engineering, LIX, pp. 30-40

Lee, S. and Choi, Y. (2016), "Reviews of Unmanned Aerial Vehicle (Drone) Technology Trends and Its Applications in the Mining Industry", Geosystem Engineering, Jul 3; Vol.19, Issue 4, pp. 197-204.

Lee, K. S., Ovinis, M., Nagarajan, T., Seulin, R. and Morel, O. (2015), "Autonomous patrol and surveillance system using unmanned aerial vehicles", Environment and Electrical Engineering (EEEIC) 2015 IEEE 15th International Conference, pp. 1291-1297.

Lippiello, V. and Siciliano, B. (2012), "Wall inspection control of a VTOL unmanned aerial vehicle based on a stereo optical flow", Intelligent Robots and Systems (IROS) 2012 IEEE/RSJ International Conference, pp. 4296-4302.

Mantey, S. and Tagoe, N. D., (2019), "Suitability of Unmanned Aerial Vehicles for Cadastral Surveys", Ghana Mining Journal, Vol. 19, No. 1, pp. 1 - 8 .

Manyoky, M., Theiler P., Steudler D., and Eisenbeiss H. (2011), "Unmanned aerial vehicle in cadastral applications", International Archives of the Photogramm-etry, Remote Sensing and Spatial Information Sciences, Vol. XXXVIII1/C22, pp. 57-62.

Merz, T. and Chapman, S. (2011), “Autonomous Unmanned Helicopter System For Remote Sensing Missions In Unknown Environm-ents", The International Archives of the Photogrammetry, Remote Sensing and Spatial Information Sciences, XXXVIII-1/C22, pp. 143148.

Miljkovi'c, S., Kuburi'c, M., Ogrizovi'c, V., Del`cev, S. and Gǔcevi'c, J. (2017), "Application of Unmanned Aerial Vehicles in determining the cubic contents of material", In Proceedings of the 5th International Conference Contemporary Achievements in Civil Engineering, Subotica, Serbia, 21 April 2017; Beševi'c, M. T., Ed.; Birografika Distribucija: Subotica, Serbia, pp. 913-919.

Park, H. J., Turner, R., Lee, D. R. and Lee, J. O. (2016), "3D Modelling of Coal Stockpiles Using 
UAV data in an Open Cut Mine Environment", 16th International Congress for Mine Surveying, Brisbane, Australia, pp. 77 - 79.

Raeva, P. L., Filipova, S. L. and Filipov, D. G. (2016), "Volume Computation of a Stockpile-A Study Case Comparing GPS and UAV Measurements in an Open Pit Quarry", International Archives of the Photogramm-etry, Remote Sensing and Spatial Information Sciences, Prague, Czech Republic, Vol. 4, No. 1, pp. 999 1003.

Rathore, I. and Kumar, N. P. (2015), "Unlocking the Potentiality of UAVs in Mining Industry and its Implications", International Journal of Innovative Research in Science, Engineering and Technology, Vol. 4, Issue 3, pp. 852 - 855.

Remondino, F., Barazzetti, L., Nex, F., Scaioni, M. and Sarazzi, D. (2011), "UAV Photogram-metry for Mapping and 3D Modeling-Current Status and Future Perspectives", International archives of the photogrammetry, remote sensing and spatial information sciences, Conference on Unmanned Aerial Vehicle in Geomatics, Zurich, Switzerland, Vol. 38, No. 1, pp. 1 - 5.

Suleman, H. A. and Baffoe, P. E. (2017), "Selecting Suitable Sites for Mine Waste Dumps Using GIS Techniques at Goldfields, Damang Mine", Ghana Mining Journal, Vol. 17, No. 1, pp. 9-17.

Valavanis, K. P. (2008), "Advances in Unmanned Aerial Vehicles: State of the Art and the Road to Autonomy", Springer Science and Business Media, Vol. 33, 543pp.

Wang, X., Al-Shabbani, Z., Sturgill, R., Kirk, A. and Dadi, G. B. (2017), "Estimating Earthwork Volumes through Use of Unmanned Aerial Systems", Transportation Research Record, Issue 2630, pp. 1-8.

Witayangkurn, A., Nagai, M., Honda, K., Dailey, M., and Shibasaki, R. (2011), "Real-Time Monitoring System Using Unmanned Aerial Vehicle Integrated With Sensor Observation Service", The International Archives of the Photogrammetry, Remote Sensing and Spatial Information Sciences, Vol. XXXVIII-1/C22, pp. 107-112.

\section{Authors}

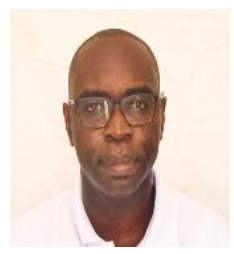

Saviour Mantey is a Senior Lecturer at the Department of Geomatic Engineering of the University of Mines and Technology (UMaT), Tarkwa, Ghana. He holds a Bachelor of Science degree in Geomatic Engineering from the Kwame Nkrumah University of Science and Technology, Kumasi, Ghana. He obtained his Master of Philosophy degree and Doctor of Philosophy from University of Cambridge and University of Mines and Technology respectively. He is Professional member of Ghana Institution of Surveyors (GhIS), a member of the Canadian Remote Sensing Society (CRSS), a member, of Aerial Cartographic and Remote Sensing Association (ACRA) and a member of Licensed Surveyors Association of Ghana (LISAG). His research interest includes application of Remote Sensing and GIS in Health and Environmental Analysis, UAVs and Web GIS applications.

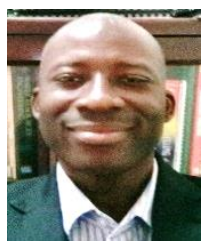

Michael S. Aduah is a Senior Lecturer at the Department of Geomatic Engineering of the University of Mines and Technology, Tarkwa, Ghana. He holds BSc in Geodetic Engineering from the Kwame Nkrumah University of Science and Technology (KNUST), a double MSc degree in Geoinformation Science and Earth Observation from University of Lund (Sweden) and ITC (The Netherlands) and a PhD in Hydrology from the University of KwaZulu Natal (UKZN), South Africa. He is a Professional Member of the Ghana Institution of Surveyors and a member of the International Association of Hydrological Science (IAHS). His research interests include the development of tools and techniques in Geoinformation Science and Earth Observation for modelling the environment, land use change analyses and modelling, surface water hydrology and assessment of global change impacts. 